\title{
Emissão de óxido nitroso associado ao uso de ureia no cultivo de melão amarelo
}

\author{
Vanessa Cláudia Vasconcelos SEGUNDO ${ }^{1 *}$, Renato INNECCO ${ }^{1}$, Ebenézer de Oliveira SILVA² \\ ${ }^{1}$ Programa de Pós-Graduação em Agronomia (Fitotecnia), Universidade Federal do Ceará, Fortaleza, CE, Brasil. \\ ${ }^{2}$ Embrapa Agroindústria Tropical, Fortaleza, CE, Brasil. \\ *E-mail:vanessac_vasconcelos@yahoo.com.br
}

Recebido em agosto/2017; Aceito em agosto/2018.

\begin{abstract}
RESUMO: O meloeiro tem grande importância econômica para o Nordeste brasileiro. Entretanto, em seu cultivo utiliza-se insumos que podem prejudicar o ambiente; como, os fertilizantes nitrogenados. Objetivou-se avaliar a emissão de $\mathrm{N}_{2} \mathrm{O}$ em cultivo de meloeiro amarelo 'Goldex'. O experimento foi instalado em delineamento inteiramente casualizado, com cinco repetições. Os tratamentos foram: 0 (controle), 1,0; 1,5 e 2 vezes a quantidade de nitrogênio recomendada para cada estádio. Foi analisado o fluxo de $\mathrm{N}_{2} \mathrm{O}$, área foliar, número de folhas, massa seca da parte aérea, massa seca dos frutos, massa seca da parte radicular, nitrogênio

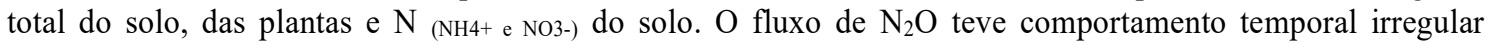
durante a fase de plântulas e crescente na floração. Os tratamentos afetaram significativamente a área foliar, número de folhas, massa seca da parte aérea, massa seca da parte radicular, nitrogênio da parte aérea e parte radicular das plantas e do solo. A aplicação de nitrogênio, em dosagens superiores à recomendada, não aumentou a produção do meloeiro. E o cálculo do fator de emissão mostrou que a emissão do $\mathrm{N}_{2} \mathrm{O}$ não atingiu valores prejudiciais ao ambiente.
\end{abstract}

Palavras-chave: fator de emissão, efeito estufa e nitrogênio.

\section{Nitrous oxide emission associated with urea use the yellow melon crop}

\begin{abstract}
The melon has great economic importance for the Brazilian Northeast. However, in its cultivation uses inputs that can harm the environment; Such as nitrogen fertilizers. The objective of this study was to evaluate the emission of $\mathrm{N}_{2} \mathrm{O}$ in yellow 'Goldex' cultivar. The experiment was installed in a completely randomized design with five replications. The treatments were: 0 (control), 1.0; 1.5 and 2 times the amount of nitrogen recommended for each stage. $\mathrm{N}_{2} \mathrm{O}$ flux, leaf area, leaf number, shoot dry mass, fruit dry mass, dry mass of the root portion, total soil nitrogen, of the plants and $\mathrm{N}_{(\mathrm{NH} 4}+$ and $\mathrm{NO}_{3}$-) of the soil were analyzed. The flow of $\mathrm{N} 2 \mathrm{O}$ had irregular temporal behavior during the seedling phase and increased in flowering. The treatments affected significantly the leaf area, number of leaves, dry mass of the aerial part, dry mass of the root part, nitrogen of the aerial part and root part of the plants and the soil. The application of nitrogen, in dosages higher than the recommended one, did not increase the production of the melon. And the calculation of the emission factor showed that the emission of $\mathrm{N}_{2} \mathrm{O}$ did not reach values harmful to the environment.
\end{abstract}

Keywords: emission fator, greenhouse and nitrogen.

\section{INTRODUÇÃO}

O Brasil é destaque no cenário mundial de produção e exportação de melão em que o Nordeste brasileiro é o maior produtor nacional, sendo que o Rio Grande do Norte foi detentor de $45 \%$ da produção em 2013 seguido por Ceará e Bahia. Segundo o Relatório de Comércio Exterior (Secex), órgão do Ministério do Desenvolvimento, Indústria e Comércio Exterior, em 2013 as exportações deste fruto totalizaram 191,4 mil toneladas e foi obtido um faturamento de US\$ 147,5 milhões (SANTOS et al., 2013).

Para a contínua obtenção de alta produtividade, os centros produtores necessitam fazer uso de tecnologia na produção, utilizando variedades mais produtivas e fertilizantes químicos mais solúveis.

De janeiro a setembro de 2014 foram consumidos quase 24 milhões de toneladas de fertilizantes minerais no Brasil. Este valor representa um aumento de 7,3\% do consumo em relação à 2013 (ANDA, 2014). Devido à grande exigência em nitrogênio pelas culturas e a deficiência desse nutriente pelos solos agrícolas brasileiros, os fertilizantes nitrogenados estão entre os mais utilizados no país. As fontes de nitrogênio mais utilizadas são a ureia e o sulfato de amônio (COSTA, 2011).

Apesar do grande benefício desses fertilizantes para o meloeiro existe o inconveniente de que o $\mathrm{N}$ quando transferido de um ecossistema para outro pode tornar-se um poluente. Este processo se dá pela liberação de óxido nitroso $\left(\mathrm{N}_{2} \mathrm{O}\right)$ como um subproduto dos processos de nitrificação e desnitrificação através da atividade microbiana do solo (FIGUEIREDO, 2012).

Segundo o Intergovernmental Panel on Climate Change (IPCC, 2007), a principal fonte de aumento da concentração de $\mathrm{N}_{2} \mathrm{O}$ se deve a agricultura. $\mathrm{O} \mathrm{N}_{2} \mathrm{O}$ tem um potencial de aquecimento global 310 vezes maior do que o dióxido de carbono $\left(\mathrm{CO}_{2}\right)$, assim), mesmo que emitido em pequenas quantidades ele é potencialmente perigoso, favorecendo o efeito estufa e a destruição da camada de ozônio.

Para a realização de inventários das emissões de gases de efeito estufa (GEE) existe uma metodologia recomendada pelo IPCC (2006), essa varia de acordo com a natureza da 
atividade (agricultura, indústria, energia e resíduos) e do gás $\left(\mathrm{CO}_{2}, \mathrm{~N}_{2} \mathrm{O}\right.$ e $\left.\mathrm{CH}_{4}\right)$. Para o cálculo de GEE em áreas de cultivo são utilizados métodos que mesclam dados relativos aos insumos aplicados, características ambientais e fatores de emissão para cada gás em estudo.

Informações ambientais para classes globais de bioma, clima, solo e fatores de emissão gerais para grupos de culturas cultivadas no mundo inteiro são fornecidas pelo IPCC (2006). Além deste, existe o inventário brasileiro, realizado em 2010, com informações ambientais mais particularizadas para biomas e solos brasileiros. Estudos relativos ao cálculo das emissões de GEE trazem um certo nível de incerteza devido aos fatores de emissão, pois os que se encontram disponíveis pelo IPCC (2006) e governo brasileiro (BRASIL, 2010) levam em conta grandes biomas, tornando imprescindível a realização de pesquisas para fornecer fatores de emissão característicos de culturas específicas e microrregiões (SANTOS et al., 2013).

Dada a importância das mudanças climáticas, este trabalho propõe avaliar a emissão de óxido nitroso em cultivo de meloeiro amarelo 'Goldex' adubado com fertilizante nitrogenado, aos 5 e 15 dias após o transplantio.

\section{MATERIAL E MÉTODOS}

O experimento foi realizado de outubro a novembro de 2014 e teve duração de 39 dias após o transplantio. Este foi executado em casa de vegetação na Embrapa Agroindústria Tropical, situada em Fortaleza - CE. As coordenadas geográficas do local são $03^{\circ} 45^{\prime} 00^{\prime \prime}$ de latitude sul e $35^{\circ} 33^{\prime}$ 00" de longitude oeste Grm e altitude de 19,53 m acima do nível do mar (FILHO et al., 2006). Fortaleza apresenta tipo climático Aw' segundo a classificação de Köppen, o que a caracteriza como uma região de clima tropical chuvoso.

$\mathrm{Na}$ condução do experimento foram utilizadas mudas de meloeiro do híbrido Goldex, pertencente ao grupo Valenciano (melão amarelo), e o cultivo foi realizado em vasos de cinco litros preenchidos com solo de textura franco arenosa advindo da estação experimental da Embrapa Agroindústria Tropical situada em Paraipaba - CE. As características químicas e físicas do mesmo encontram-se na Tabela 1.

Tabela1. Análise de solo anterior a instalação do experimento, Fortaleza - CE, 2014

Table 1. Soil analysis prior to installation of the experiment, Fortaleza - CE, 2014.

Complexo Sortivo

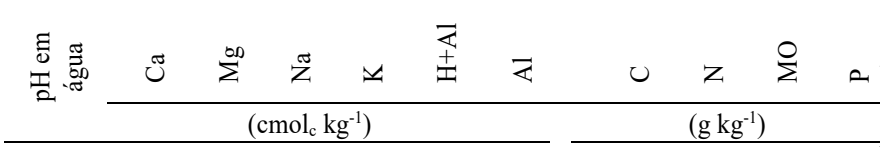

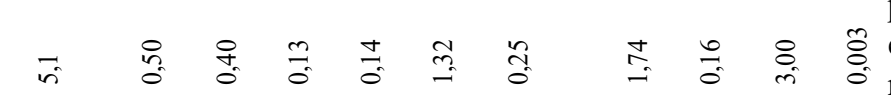

\begin{tabular}{llccc}
\hline \multicolumn{5}{c}{ Composição granulométrica $\left(\mathrm{g} \mathrm{kg}^{-1}\right)$} \\
\hline $\begin{array}{l}\text { Areia } \\
\text { grossa }\end{array}$ & $\begin{array}{l}\text { Areia } \\
\text { fina }\end{array}$ & Silte & Argila & $\begin{array}{c}\text { Argila } \\
\text { Natural }\end{array}$ \\
\hline 637 & 252 & 5 & 106 & 28 \\
\hline
\end{tabular}

Em cada vaso foi cultivada uma planta. A irrigação foi realizada diariamente de forma manual durante a execução do experimento. A adubação, com exceção da fonte de nitrogênio, foi realizada seguindo o sugerido por Bezerra
(2011) para o meloeiro com base na CE do solo, esta foi aplicada diariamente, com exceção dos finais de semana, através de solução nutritiva acrescida ao solo no momento em que foi procedida a irrigação. O delineamento utilizado foi o inteiramente casualizado com cinco repetições. Os quatro tratamentos foram assim definidos: 0 (controle), 1,0; 1,5 e 2 vezes a quantidade de nitrogênio recomendada por Crisóstomo et al. (2002) (Tabela 2). A aplicação da ureia foi realizada em sulco próximo a planta e foi parcelada em duas vezes, sendo uma aplicada na ocasião do transplantio das mudas para os vasos (fase de plântulas) e a outra na floração. Sempre após as adubações nitrogenadas foram realizadas irrigações.

Tabela 2. Quantidade de fertilizante nitrogenado aplicado por vaso em diferentes períodos, Fortaleza, CE, 2014.

Table 2. Quantity of nitrogen fertilizer applied per pot in different periods, Fortaleza, CE, 2014.

\begin{tabular}{|c|c|c|c|c|c|c|c|c|c|c|c|}
\hline \multicolumn{12}{|c|}{ Fertilizante $\mathrm{mL} \cdot \mathrm{vaso}^{-1} \cdot \mathrm{dia}^{-1}$} \\
\hline \multicolumn{4}{|c|}{ Macronutrientes } & & & \multicolumn{6}{|c|}{ Micronutrientes } \\
\hline 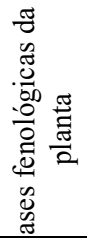 & 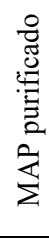 & $\begin{array}{l}D_{\infty}^{+} \\
\sum_{\infty}^{\infty}\end{array}$ & $\underset{\forall}{\circlearrowright}$ & 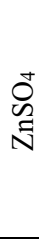 & $\underset{ٍ}{\Xi}$ & $\underset{\Xi}{\stackrel{\Xi}{\Xi}}$ & 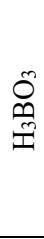 & 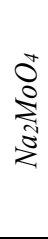 & $\begin{array}{l}0 \\
0 \\
0 \\
0\end{array}$ & 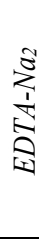 & 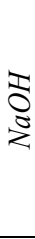 \\
\hline$\frac{\text { 导 }}{\underset{E}{\stackrel{E}{E}}}$ & $\stackrel{\infty}{\sigma}$ & $\stackrel{\infty}{\sim}$ & $\stackrel{\infty}{\sim}$ & $\frac{\sqrt{0}}{0}$ & $\frac{\sim}{0}$ & $\frac{N}{0}$ & $\frac{\sim}{0}$ & $\frac{\sim}{0}$ & $\frac{\sim}{0}$ & $\frac{N}{0}$ & $\frac{1}{0}$ \\
\hline 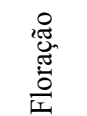 & $\underset{m}{8}$ & $\underset{m}{8}$ & $\underset{m}{8}$ & $\frac{N}{0}$ & $\frac{1}{0}$ & $\frac{N}{0}$ & $\frac{\sim}{0}$ & $\frac{\sim}{0}$ & $\frac{\sim}{0}$ & $\frac{1}{0}$ & $\frac{N}{0}$ \\
\hline
\end{tabular}

Para a quantificação da emissão de óxido nitroso foram utilizadas câmaras estáticas fechadas, uma em cada vaso. Estas foram confeccionadas em cloreto de polivinila (PVC) com $0,15 \mathrm{~m}$ de diâmetro e $0,20 \mathrm{~m}$ de altura, inseridas no solo até $0,05 \mathrm{~m}$ de profundidade cinco dias antes da primeira coleta e mantidas no local durante todo o período de coleta de gases, diminuindo assim efeitos de perturbação da estrutura do solo e nas raízes do meloeiro.

Em ocasião do recolhimento de amostras de gases, a tampa de cada câmara, constituída por um cilindro de PVC contendo dois septos de borracha e um suspiro para manter o equilíbrio da pressão, foi acoplada à sua extremidade superior. Para o monitoramento da temperatura no interior das câmaras durante as amostragens foi inserido um termômetro digital em um dos septos. Através do outro septo as amostras de gás foram retiradas com auxílio de seringas de polipropileno de $20 \mathrm{~mL}$ e em seguida estas foram injetadas em frascos de $22 \mathrm{~mL}$ que previamente foram submetidos a realização de vácuo.

As coletas de gás duraram cinco dias a partir da aplicação de ureia (nitrogênio) no solo e foram realizadas sempre no intervalo de 7:00 às 10:00 h para amenizar o efeito de altas temperaturas sobre a emissão de gases. Para cada câmara, foram coletadas amostras em duplicata nos instantes zero e quarenta e cinco minutos, perfazendo quatro amostras por câmara. A análise das amostras de gás foi realizada no Laboratório de Pós Colheita da Embrapa Agroindústria Tropical (Fortaleza - CE). Para a determinação da 
concentração de $\mathrm{N}_{2} \mathrm{O}$, foi utilizado cromatógrafo gasoso da marca Bruker (450 GC), equipado com detector por ionização de chama (FID) a $200^{\circ} \mathrm{C}$, com coluna empacotada Porapak - Q a $50^{\circ} \mathrm{C}$, gás de arraste hélio a um fluxo de 50 $\mathrm{mL} \cdot \mathrm{min}^{-1}$ e injeção de volume de amostra de $1 \mathrm{~mL}$ a $120^{\circ} \mathrm{C}$. Um gás padrão de $\mathrm{N}_{2} \mathrm{O}$ na concentração de 1090 ppbv de $\mathrm{N}_{2} \mathrm{O}$ em $\mathrm{N}_{2}$ foi injetado e a partir do qual, por regra de três, os teores de $\mathrm{N}_{2} \mathrm{O}$ nas amostras foram calculados. Os fluxos de $\mathrm{N}_{2} \mathrm{O}\left(\mathrm{FN}_{2} \mathrm{O}\right)$ foram calculados pela equação (1) descrita por Barton et al. (2008).

$$
\mathrm{FN}_{2} \mathrm{O}=\delta \mathrm{C} / \delta \mathrm{t} \cdot(\mathrm{V} / \mathrm{A}) \cdot \mathrm{M} / \mathrm{Vm}, \mu \mathrm{g} \mathrm{N}-\mathrm{N}_{2} \mathrm{O} \mathrm{m} \mathrm{m}^{-2} \cdot \mathrm{h}^{-1} \text { (Eq. 1) }
$$

em que $\mathrm{FN}_{2} \mathrm{O}$ : é o fluxo de $\mathrm{N}_{2} \mathrm{O}\left(\mu \mathrm{g} \mathrm{N}-\mathrm{N}_{2} \mathrm{O} \mathrm{m} \mathrm{m}^{-2} \cdot \mathrm{h}^{-1}\right) ; \delta \mathrm{C} / \delta \mathrm{t}$ : é a mudança de concentração de $\mathrm{N}_{2} \mathrm{O}$ na câmara no intervalo de incubação; V: é o volume da câmara ; $\mathrm{A}$ : é a área de solo coberta pela câmara; M: é o peso molecular de $\mathrm{N}_{2} \mathrm{O}$; Vm: é o volume molar nas Condições Normais de Temperatura e Pressão, corrigido para a temperatura e pressão no interior da câmara no momento de amostragem.

Para a determinação do fator de emissão do $\mathrm{N}_{2} \mathrm{O}$ proveniente do fertilizante sintético foi utilizado o sistema proposto por Madari et al. (2007), de acordo com a equação (2):

$$
\mathrm{FE} \%=(\mathrm{NE} / \mathrm{NA}) * 100
$$

em que FE: é o fator de emissão do $\mathrm{N}_{2} \mathrm{O}(\%)$; $\mathrm{NE}$ : é a quantidade de $\mathrm{N}-\mathrm{N}_{2} \mathrm{O}$ emitida total $\left(\mu \mathrm{g} \mathrm{N}_{2} \mathrm{O} / \mathrm{m}^{-2}\right)$; NA: é a quantidade de $\mathrm{N}$ aplicada via fertilização com uréia $\left(\mu \mathrm{g} \mathrm{N} / \mathrm{m}^{-2}\right)$.

As análises relacionadas ao desenvolvimento vegetal dos meloeiros foram realizadas aos 39 dias após o transplantio (DAT) quando as plantas se encontravam no início da frutificação. Neste momento também foram coletadas amostras de solo para posteriores análises de $\mathrm{N}_{\text {total }}$ e $\mathrm{N}_{(\mathrm{NH} 4+\text {; }}$ NO3-) presentes no solo. Para as análises relativas ao desenvolvimento vegetal as plantas foram removidas dos vasos e foram separadas em parte aérea (caule e folhas), frutos e parte radicular. Logo após isto as avaliações foram procedidas no Laboratório de Pós Colheita da Embrapa Agroindústria Tropical (Fortaleza - $\mathrm{CE}$ ). A variável número de folhas foi determinada através de contagem. A avaliação da área foliar foi efetuada através do equipamento LI 3100C Area Meter. Para a determinação da massa seca da parte aérea, frutos e parte radicular foi realizada a secagem de cada fração da planta em estufa com circulação forçada de ar a uma temperatura de $60^{\circ} \mathrm{C}$ por 72 horas e em seguida este foi pesado em balança digital.

Análises químicas foram realizadas no laboratório de Solos e Água, da Universidade Federal do Ceará (Fortaleza $\mathrm{CE}$ ), para a determinação do nitrogênio presente no material vegetal e solo aos 39 DAT. Para a determinação do $\mathrm{N}$ total foi utilizado o método de Kjeldahl através de digestão sulfúrica. O mesmo procedimento foi seguido para as análises de $\mathrm{N}$ total na planta. Também foram realizadas análises de $\mathrm{N}$ para quantificar $\mathrm{NH}_{4}{ }^{+}$e $\mathrm{NO}_{3}{ }^{-}$do solo, para tal foram realizadas extrações com solução de $\mathrm{KCl}$. Para as análises de $\mathrm{N}$ foram utilizadas 5 amostras de cada tipo de material por tratamento, totalizando em 20 amostras.

Os dados obtidos para as variáveis área foliar, número de folhas, massa seca da parte aérea, dos frutos e da raiz, nitrogênio total do solo, da parte aérea, dos frutos e da raiz e $\mathrm{NH}_{4}{ }^{+}$e $\mathrm{NO}_{3}{ }^{-}$do solo, foram submetidas a análise de regressão e a escolha dos modelos que melhor se ajustaram teve como base a significância dos coeficientes de regressão. Análises descritivas (média \pm erro padrão) foram utilizadas para demonstrar o fluxo diário de óxido nitroso.

\section{RESULTADOS}

Ocorreu aumento do fluxo médio de $\mathrm{N}_{2} \mathrm{O}$ quando o tratamento controle foi comparado aos tratamentos com nitrogênio. Entretanto, o aumento do fluxo médio de $\mathrm{N}_{2} \mathrm{O}$ entre os tratamentos com $\mathrm{N}$ foram baixos (Figura 1). Na fase de plântulas, em que o solo se encontrava totalmente seco e carente em nitrogênio, o fluxo de $\mathrm{N}_{2} \mathrm{O}$ apresentou uma variação temporal irregular (Figura 1a). Foi observado uma variação temporal crescente do fluxo de $\mathrm{N}_{2} \mathrm{O}$ para os tratamentos que receberam nitrogênio durante a floração do melão (Figura 1b).

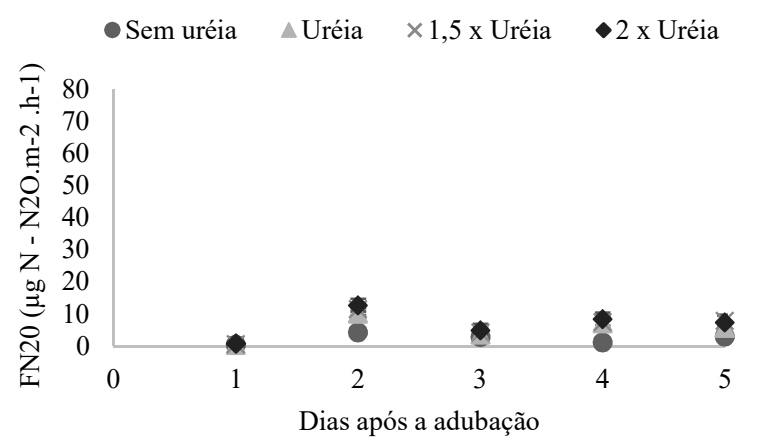

(B)

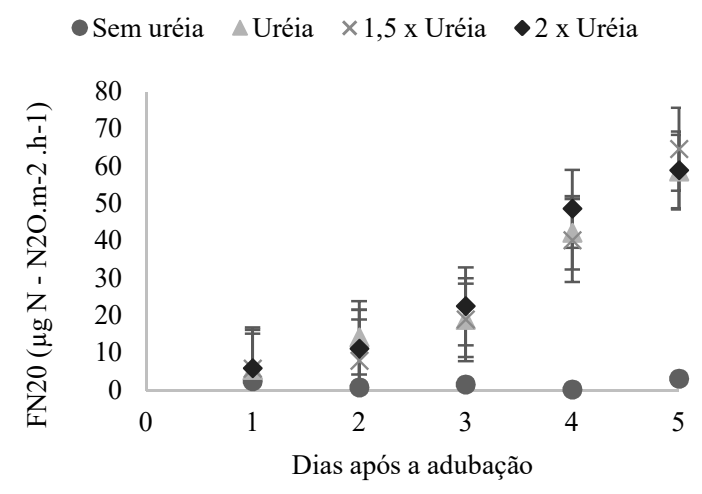

Figura 1. Variações temporais do fluxo de óxido nitroso em cultivo de melão (Cucumis melo) em relação a crescentes doses de ureia durante a fase de plântulas (A) e floração (B), Fortaleza, CE, 2014.

Figure 1. Temporal variations of the nitrous oxide flow in melon cultivation (Cucumis melo) in relation to increasing doses of urea during the seedling phase (A) and floration (B), Fortaleza, CE, 2014.

O maior fator de emissão $(0,51 \%)$ foi verificado no tratamento com a menor quantidade de ureia (Tabela 3 ). Na Tabela 4 encontra-se o resumo da análise de variância para o efeito de ausência e de crescentes doses de nitrogênio na forma de ureia sobre o nitrogênio total do solo e da parte aérea, frutos e raízes de meloeiro e $\mathrm{NH} 4+$ e NO3- do solo.

Foi observado que crescentes doses de ureia proporcionaram efeitos significativos $(\mathrm{p}<0,05)$ para o $\mathrm{N}$ da parte aérea, $\mathrm{N}$ da parte radicular e $\mathrm{N}$ total do solo. A análise 
de ausência e presença de adubação nitrogenada sobre os teores de nitrogênio na parte aérea, radicular e no solo foram realizados através de regressão polinomial e para todas as variáveis verificou-se que o modelo de regressão quadrático foi o que melhor se ajustou para explicar a variação das mesmas aos 34 DAT.

Com respeito a parte aérea e ao sistema radicular (Figura 2 ), as doses de ureia tiveram influência sobre o $\mathrm{N}$ vegetal. Quanto ao $\mathrm{N}$ total do solo (Figura 2c), este somente foi significativo quando comparado a aplicação e não aplicação de ureia, pois doses crescentes não influenciaram no $\mathrm{N}$ total do solo.

Tabela 3. Emissões totais e fatores de emissão para o $\mathrm{N}_{2} \mathrm{O}$ durante o cultivo de melão (Cucumis melo) em relação a crescentes doses de uréia, Fortaleza - CE, 2014.

Table 3. Total emissions and emission factors for $\mathrm{N}_{2} \mathrm{O}$ during melon cultivation (Cucumis melo) in relation to increasing urea doses, Fortaleza - CE, 2014.

\begin{tabular}{lccc}
\hline Tratamentos & $\begin{array}{c}\text { Emissão } \\
\text { total } \\
\left(\mu \mathrm{g} \mathrm{N}-\mathrm{N}_{2} \mathrm{O} \cdot \mathrm{m}^{-2}\right)\end{array}$ & $\begin{array}{c}\text { Nitrogênio } \\
\text { aplicado } \\
\left(\mu \mathrm{g} \mathrm{N} \cdot \mathrm{m}^{-2}\right)\end{array}$ & $\begin{array}{c}\text { Fator de } \\
\text { emissão } \\
(\%)\end{array}$ \\
\hline Sem uréia & 1760 & - & - \\
1,0 x Uréia & 18545 & 3000000 & 0,51 \\
1,5 x Uréia & 18665 & 4500000 & 0,34 \\
2,0 x Uréia & 19987 & 6000000 & 0,28 \\
\hline
\end{tabular}

Tabela 4. Resumo da análise de variância das variáveis nitrogênio da parte aérea da planta (N - PA), nitrogênio do fruto (NF), nitrogênio da parte radicular (NPR), nitrogênio total do solo (N total) e teor de amônio e nitrato do solo $\left(\mathrm{NH}_{4}{ }^{+}\right.$e $\left.\mathrm{NO}_{3}{ }^{-}\right)$, Fortaleza CE, 2014.

Table 4. Summary of the analysis of variance of the variables of aerial part of plant nitrogen (AP-N), fruit nitrogen $(\mathrm{FN})$, root nitrogen $(\mathrm{RN})$, total soil nitrogen $(\mathrm{N}$ - total) and ammonium content And soil nitrate $\left(\mathrm{NH}_{4}{ }^{+}\right.$and $\left.\mathrm{NO}_{3}{ }^{-}\right)$, Fortaleza - CE, 2014.

\begin{tabular}{|c|c|c|c|c|c|c|}
\hline \multirow[t]{2}{*}{$\mathrm{FV}$} & \multirow[t]{2}{*}{ GL } & \multicolumn{5}{|c|}{ QM } \\
\hline & & $\begin{array}{r}\mathrm{N}-\mathrm{PA} \\
\mathrm{g} \mathrm{pl}^{-1}\end{array}$ & $\begin{array}{l}\mathrm{N}-\mathrm{F} \\
\mathrm{g} \mathrm{pl}^{-1}\end{array}$ & $\begin{array}{c}\mathrm{N}-\mathrm{PR} \\
\mathrm{g} \mathrm{pl}^{-1}\end{array}$ & $\begin{array}{l}\mathrm{N}-\text { total }^{-1} \\
\mathrm{~g} \text { vaso }^{-1}\end{array}$ & $\begin{array}{c}\mathrm{NH}_{4}{ }^{+} \\
\mathrm{NO}_{3}{ }^{-} \\
\text {g vaso }^{-1}\end{array}$ \\
\hline $\begin{array}{l}\text { Tratamentos } \\
\text { (T) }\end{array}$ & 3 & $0,089^{*}$ & $0,007^{\mathrm{ns}}$ & $0,000 *$ & $0,186^{*}$ & $0,001^{\mathrm{ns}}$ \\
\hline Resíduo & 16 & 0,006 & 0,008 & 0,000 & 0,015 & 0,000 \\
\hline CV (\%) & & 29,38 & 101,18 & 33,92 & 22,00 & 29,53 \\
\hline
\end{tabular}

${ }^{\mathrm{ns}}$ não significativo; * significativo a $5 \%$ de probabilidade pelo teste $\mathrm{F}$.

Foi observado que crescentes doses de ureia proporcionaram efeitos significativos $(\mathrm{p}<0,05)$ para o $\mathrm{N}$ da parte aérea, $\mathrm{N}$ da parte radicular e $\mathrm{N}$ total do solo. A análise de ausência e presença de adubação nitrogenada sobre os teores de nitrogênio na parte aérea, radicular e no solo foram realizados através de regressão polinomial e para todas as variáveis verificou-se que o modelo de regressão quadrático foi o que melhor se ajustou para explicar a variação das mesmas aos 34 DAT.

Com respeito a parte aérea e ao sistema radicular (Figura $2 \mathrm{a}$ e $2 \mathrm{~b}$ ), as doses de ureia tiveram influência sobre o $\mathrm{N}$ vegetal. Quanto ao N total do solo (Figura 2c), este somente foi significativo quando comparado a aplicação e não aplicação de ureia, pois doses crescentes não influenciaram no $\mathrm{N}$ total do solo.

Na Tabela 5 encontra-se o resumo da análise de variância para o efeito de ausência e crescentes doses de nitrogênio na forma de ureia sobre a área foliar, número de folhas, massa seca da parte aérea, massa seca dos frutos, massa seca das raízes. $\mathrm{Na}$ espécie em estudo foi averiguado que, crescentes doses de ureia afetaram significativamente $(\mathrm{p}<0,05)$ a área foliar, o número de folhas, a massa seca da parte aérea e a massa seca das raízes. Apenas a massa seca dos frutos não foi afetada significativamente pelos tratamentos em estudo.

(A)

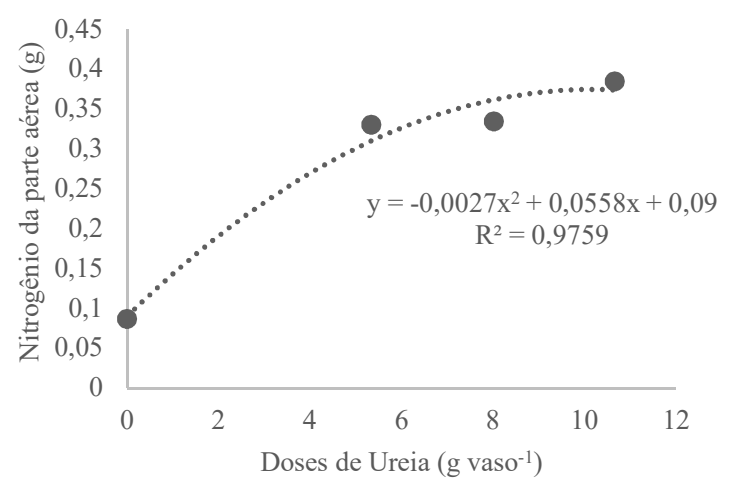

(B)

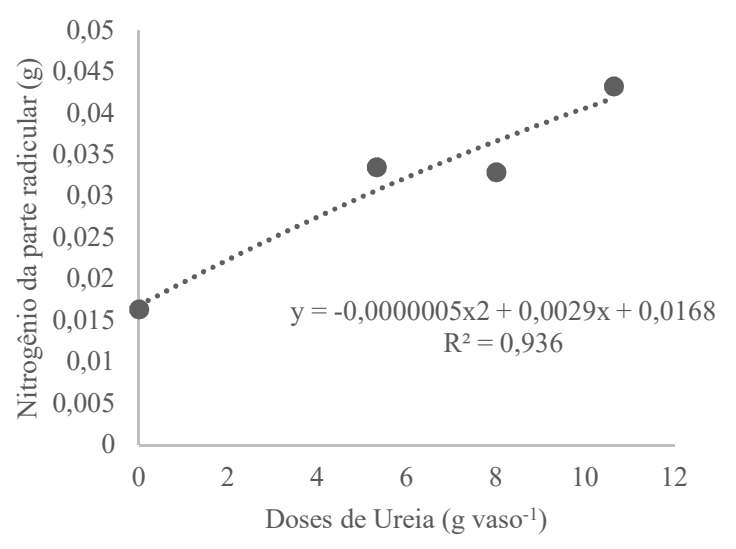

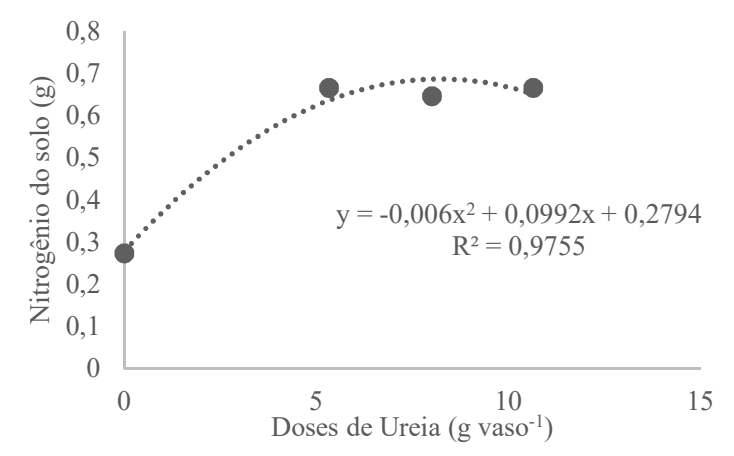

Figura 2. Nitrogênio da parte aérea (A), da parte radicular (B) da planta e total do solo, em cultivo de melão (Cucumis melo) em relação a crescentes doses de ureia, Fortaleza, CE, 2014.

Figure 2. Nitrogen from the aerial part $(\mathrm{AB})$, root part $(\mathrm{B})$ and total soil $(\mathrm{C})$ of the plant in melon cultivation (Cucumis melo) in relation to increasing doses of urea, Fortaleza, CE, 2014.

A análise de ausência e presença de adubação nitrogenada sobre os rendimentos da área foliar, número de folhas, massa seca da parte aérea e massa seca da parte radicular foram realizados através de regressão polinomial e para todas as variáveis verificou-se que o modelo de regressão quadrático foi o que melhor se ajustou para explicar a variação das mesmas durante o desenvolvimento de meloeiro em casa de vegetação (Figura 3). Os valores de área foliar total foram 
crescentes quando o controle foi comparado aos tratamentos com adubação nitrogenada. Sendo que os tratamentos com diferentes dosagens de ureia apresentaram uma tendência linear entre os mesmos. A máxima produção de área foliar, $1671,87 \mathrm{~cm}^{2}$, foi estimada com a dose de $8,23 \mathrm{~g} \mathrm{vaso}^{-1} \mathrm{de}$ ureia (Figura 3a).

Tabela 5. Resumo da análise de variância das variáveis área foliar total (AFT), número de folhas (NFO), massa seca da parte aérea (MSA), massa seca da parte radícula (MSR), massa seca dos frutos (MSF), considerando diferentes dosagens de nitrogênio, Fortaleza CE, 2014.

Table 5. Summary of the analysis of variance of the variables total leaf area (TLA), number of leaves (NL), dry mass of the aerial part (DMA), dry mass of the root part (DMR), dry mass of the fruit (DMF), considering different nitrogen dosages Fortaleza - CE, 2014.

\begin{tabular}{lcccccc}
\hline FV & GL & \multicolumn{5}{c}{ QM } \\
\cline { 3 - 7 } & & AFT & NFO & MAS & MSR & MSF \\
\hline Tempo(T) & 3 & $1440219,2^{*}$ & $482,93^{*}$ & $104,31^{*}$ & $0,445^{*}$ & $8,03^{\text {ns }}$ \\
Resíduo & 16 & 53263,7 & 64,03 & 5,12 & 0,092 & 11,35 \\
\hline CV (\%) & 17,35 & 20,62 & 19,35 & 23,27 & 93,22 \\
\hline
\end{tabular}

${ }^{\mathrm{ns}}$ não significativo; * significativo a $5 \%$ de probabilidade pelo teste $\mathrm{F}$.

Quanto a variável número de folhas do meloeiro, verificase que a mesma foi influenciada significativamente pelas doses de nitrogênio quando estas foram comparadas ao controle, porém, entre si não foi observado um aumento crescente. O ponto de máxima produção desta variável se dá com a dosagem de $8,16 \mathrm{~g}_{\text {vaso }^{-1}}$ de ureia com um número de 45 folhas planta $^{-1}$ (Figura 3b).

Já a massa seca da parte aérea aumentou consideravelmente do tratamento controle para os tratamentos com diferentes concentrações de N. No entanto, entre os tratamentos com $\mathrm{N}$ não ocorreu um comportamento crescente. Para esta variável a máxima produção, 14,62 g planta $^{-1}$, pode ser alcançada com a dose de $8,33 \mathrm{~g}$ de ureia (Figura 3c). O peso da massa seca da parte radicular apresentou aumento crescente de acordo com o acréscimo de N. A dosagem de 12,52 gplanta $^{-1}$ de ureia proporcionou a máxima produção desta variável, $1,55 \mathrm{~g} \mathrm{planta}^{-1}$ (Figura $3 \mathrm{~d}$ ).

\section{DISCUSSÃO}

$\mathrm{Na}$ fase de plântulas ao propiciar condições adequadas aos microrganismos do solo, por ocasião da primeira adubação e adição de água ao solo via irrigação, estes aumentaram excessivamente as suas atividades e o pico de emissão de $\mathrm{N}_{2} \mathrm{O}$ ocorreu no segundo dia após a adubação. Posteriormente foi atingido um equilíbrio do fluxo de $\mathrm{N}_{2} \mathrm{O}$. Assim como, ocorreu com a cultura do feijão em área de cerrado ao receber fertilização nitrogenada em cobertura após a semeadura (COSTA, 2011). Isto ocorreu em consequência do conteúdo de $\mathrm{N}$ mineral ser um possível indicador dos processos de nitrificação e desnitrificação (LUDWING et al., 2001).

Durante a floração do melão os maiores fluxos de $\mathrm{N}_{2} \mathrm{O}$, em detrimento a fase de plântulas, deve-se à maior dosagem de $\mathrm{N}$ aplicada e também pode ser atribuída a menores perdas do nutriente por lixiviação visto que neste estádio o sistema radicular da planta já se encontrava desenvolvido.

A temperatura também pode ter influenciado o maior fluxo de $\mathrm{N}_{2} \mathrm{O}$, visto que Liu et al. (2010) observaram aumento da produção de $\mathrm{N}_{2} \mathrm{O}$ à medida que a temperatura aumentava. Eles observaram o pico máximo de emissão na faixa de temperatura entre $17^{\circ} \mathrm{C}$ e $30^{\circ} \mathrm{C}$. Neste estudo a temperatura próxima ao solo teve uma média de $33^{\circ} \mathrm{C}$ durante o período de coleta dos gases. O efeito desta acrescida ao suprimento de $\mathrm{N}$ mineral influenciaram $\mathrm{O}$ aumento gradativo do fluxo de $\mathrm{N}_{2} \mathrm{O}$ com relação a crescentes doses de nitrogênio. Pois, o aumento da temperatura promove aumento da atividade enzimática e consequentemente liberação de $\mathrm{N}_{2} \mathrm{O}$ pelos processos microbiológicos de nitrificação e desnitrificação (LUDWING et al., 2001).

(A)

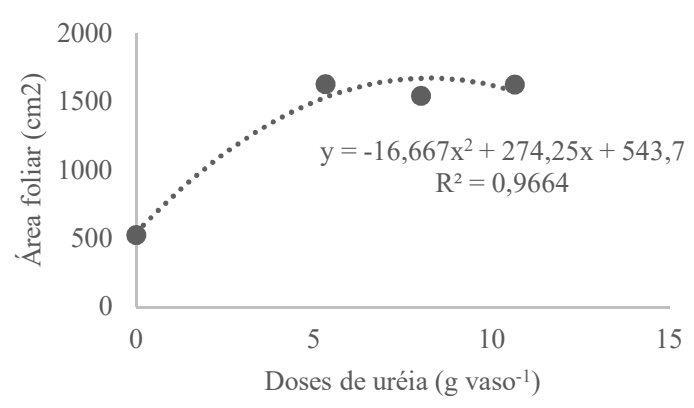

(B)

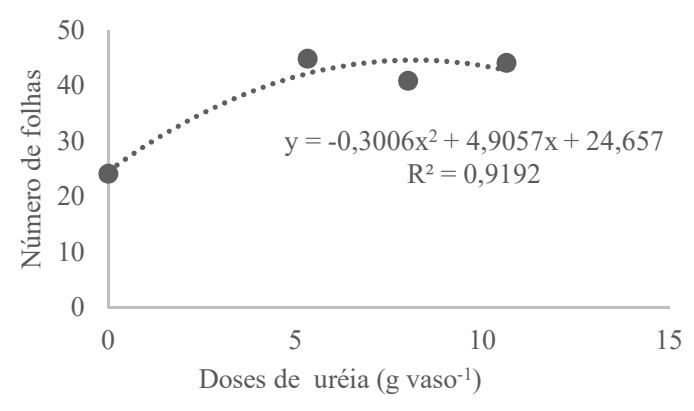

(C)

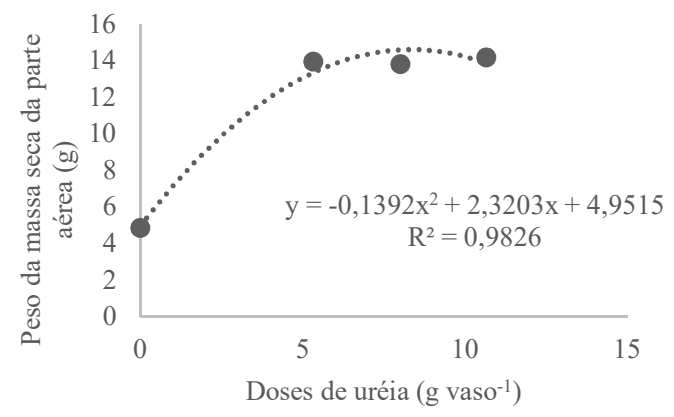

(D)

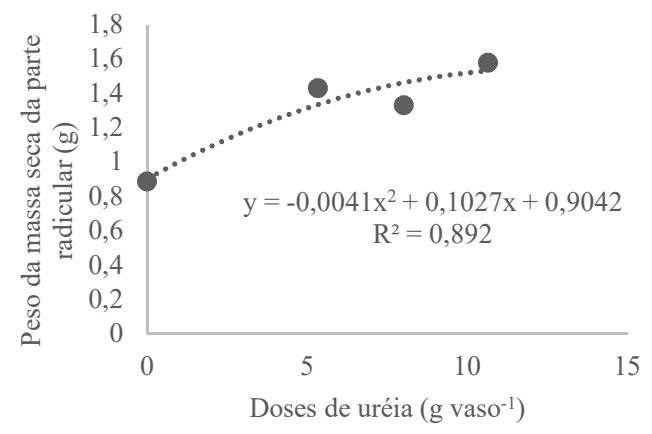

Figura 3. Área foliar (A), número de folhas (B), massa seca da parte aérea (C) e radicular (D) de melão (Cucumis melo) em relação a crescentes doses de ureia, Fortaleza - CE, 2014.

Figure 3. Leaf area (A), leaves number (B), dry mass aerial (C) and root part (D) of melon (Cucumis melo) plants in relation to increasing doses of urea, Fortaleza - CE, 2014. 
$\mathrm{O}$ fator de emissão de $\mathrm{N}_{2} \mathrm{O}$ não pode ultrapassar o valor de $1 \%$ (IPCC, 2007). Assim, o cultivo do melão nas condições edafoclimáticas do presente estudo estão dentro do permitido. Pois, o maior fator de emissão $(0,51 \%)$ foi verificado no tratamento com a menor quantidade de ureia (tabela 3). Isto ocorreu, provavelmente, devido a provável baixa população de microrganismos do solo, o que ocasionou reduzida produção de $\mathrm{N}_{2} \mathrm{O}$.

Com respeito a parte aérea e ao sistema radicular (gráfico $2 \mathrm{a}$ e $2 \mathrm{~b}$ ), as doses de ureia tiveram influência sobre o $\mathrm{N}$ vegetal, isto, porque o nitrogênio é o elemento formador da estrutura da planta, sendo constituinte da estrutura de aminoácidos, proteínas, vitaminas, clorofila, enzimas e coenzimas. Também é ativador enzimático, atua nos processos de absorção iônica, fotossíntese, respiração, sínteses, crescimento vegetativo e herança (EMBRAPA, 2010). Assim, este nutriente pode ser encontrado em maior concentração nestas duas partes da planta. Portanto, em solos franco arenosos, a aplicação de doses crescentes de ureia, geralmente, vai refletir em maiores concentrações de $\mathrm{N}$ na parte aérea e no sistema radicular das plantas.

Com relação ao $\mathrm{N}$ total do solo o resultado obtido pode estar relacionado ao tipo de solo utilizado no cultivo. Solos franco arenosos são deficitários na adsorção de N, isto porque a fração mineral é composta principalmente de areia, apresenta pouca matéria orgânica e a parte hídrica é constantemente renovada (poucos vasos capilares).

A ureia tem como vantagens o elevado teor de N (45\%), alta solubilidade, sendo prontamente disponível para as plantas, entretanto, é mais susceptível às perdas de $\mathrm{N}$ por imobilização, volatilização e lixiviação (OKUMURA; MARIANO, 2012). A imobilização, provavelmente, teve baixa ocorrência, visto que a partir da análise de solo a quantidade de $\mathrm{C}$ presente no mesmo era baixa e não houve adição de matéria orgânica, necessária para propiciar uma alta relação C:N (20:1 a 25:1) e causar imobilização do N por microrganismos do solo (OKUMURA; MARIANO, 2012; SOUZA; MELO, 2000).

Quanto a volatilização de amônia também acredita-se que houve baixa ocorrência da mesma, visto que após a aplicação da ureia foi realizado umedecimento do solo, procedimento que favorece o transporte de $\mathrm{NH}_{4}{ }^{+}$e $\mathrm{OH}^{-}$para o interior do solo para que posteriormente esse seja transformado em $\mathrm{NO}_{2}^{-}$ e em seguida $\mathrm{NO}_{3}{ }^{-}$. E também para que ocorra a adsorção de $\mathrm{OH}^{-}$pelo solo durante a hidrólise da ureia interrompendo a formação e liberação de $\mathrm{NH}_{3}$. Este processo é mais efetivo em solos com $\mathrm{pH}$ baixo como era o caso do solo utilizado no presente estudo.

Já no que concerne a lixiviação esta é dependente do tipo de solo sendo os argilosos e solos com matéria orgânica menos susceptíveis a este tipo de perda. Esta condição era oposta a encontrada neste estudo o que pode ter favorecido este processo. Logo, as características físicas do solo utilizado (88,9\% areia grossa e areia fina; $0,05 \%$ silte; $13,4 \%$ argila) afetaram a atividade microbiana do solo, referente aos processos de nitrificação e desnitrificação, visto que ocorreu pouca retenção de $\mathrm{N}$ no solo e, por consequência, baixa emissão de $\mathrm{N}_{2} \mathrm{O}$.

No que diz respeito a área foliar Filho et al. (2014) trabalharam com melão cantaloupe no município de Pentecoste - CE e diferentes parcelamentos para uma quantidade de $90 \mathrm{~kg} \mathrm{ha}^{-1}$ de $\mathrm{N}$ utilizando ureia. Aos 66 dias após a emergência, verificaram que o parcelamento da quantidade total de fertilizante resultou em menores concentrações de fornecimento do nutriente por fase fenológica das plantas e assim como no presente trabalho foi obtido maior área foliar, indicando melhor desenvolvimento da parte aérea devido ao melhor aproveitamento do nutriente pela planta e a menor perda do mesmo por lixiviação.

Gratieri (2012) ao trabalhar com meloeiro pele de sapo cultivado em fibra de coco e fertirrigado com crescentes doses de nitrogênio ( 8 a $20 \mathrm{mmol} \mathrm{L}^{-1}$ ) em Minas Gerais, encontrou valores de área foliar maiores ao utilizar a maior concentração do nutriente. O autor obteve um incremento da área foliar de $32,4 \%$ em relação ao tratamento com ausência de ureia. Os resultados obtidos no presente estudo podem ter ocorrido devido, principalmente, a dois fatores: capacidade de absorção de nutrientes pela planta e permanência do nutriente no solo.

Primeiro, para que ocorra a absorção de $\mathrm{N}$ pela planta este deve estar na forma de $\mathrm{NH}_{4}{ }^{+}$e $\mathrm{NO}_{3}{ }^{-}$. Como a fonte do $\mathrm{N}$ aplicado foi a ureia $\left(\mathrm{CO}\left(\mathrm{NH}_{2}\right)_{2}\right)$, para que o mesmo seja absorvido é necessário que o fertilizante seja transformado pelos microrganismos do solo. Por tratar-se de solo franco arenoso, geralmente, com baixo nível de microrganismos, essa transformação pode ter sido deficitária.

Segundo, além da pouca transformação, o $\mathrm{N}$ na forma de nitrato $\left(\mathrm{NO}_{3}{ }^{-}\right)$não é adsorvido pela matriz do solo, resta apenas a forma adsorvida de $\mathrm{NH}_{4}{ }^{+}$. Assim, a permanência do $\mathrm{N}$ no solo é limitada. Sendo necessária seu parcelamento, como foi verificado pelos autores acima.

Diante do exposto, verifica-se que o nitrogênio é um elemento essencial para o crescimento da área foliar do meloeiro e deve ser utilizada na dosagem recomendada (120 $\mathrm{kg} \mathrm{ha}{ }^{-1}$ ), pois, como pode-se observar neste trabalho, dosagens acima do que é recomendado não afetaram a área foliar do meloeiro cultivado em solo arenoso. Entretanto, conforme observado por Gratieri (2012) esta condição pode ser diferente de acordo com as condições experimentais.

Ao avaliar o número de folhas em meloeiros pertencentes ao grupo cantaloupensis cultivados em vasos preenchidos com solo argiloso em Pombal - PB e diferentes concentrações de nitrogênio $\left(5,5\right.$ a $8,5 \mathrm{~g}$ de $\mathrm{N}$ planta $\left.{ }^{-1}\right)$ na forma de nitrato de cálcio, Fernandes et al. (2010), verificaram aos 62 dias após o transplantio, que a concentração que proporcionou o maior número de folhas para o meloeiro foi a intermediária, $6,90 \mathrm{~g} \mathrm{de} \mathrm{N} \mathrm{pl}^{-1}$.

Gratieri (2012) encontrou resultados diferentes aos 40 dias após o transplantio, em que o maior número de folhas encontrado foi observado no tratamento com a maior concentração de nitrogênio, $20 \mathrm{mmol} \mathrm{L}^{-1}$.

No estudo da fitomassa seca total de melão pele de sapo Temóteo et al. (2010) trabalharam com dosagens crescentes de nitrogênio durante o cultivo, em condições de campo em Mossoró - RN, verificaram que não ocorreu aumento da fitomassa seca total ao aplicar dosagens maiores do que a menor concentração aplicada $\left(90 \mathrm{kgha}^{-1}\right)$.

Em contrapartida Silva (2012) observou aumento da matéria seca da parte aérea do melão tipo cantaloupe, cultivado em vaso e em casa de vegetação em Rondonópolis - MT, em consequência de doses crescentes de nitrogênio que variaram de 0 a $160 \mathrm{mg} \mathrm{dm}^{-3}$. No presente estudo a falta de nitrogênio no tratamento controle proporcionou menor acúmulo de fitomassa seca da parte aérea, isto ocorreu em 
razão da provável baixa atividade fotossintética, visto que o nitrogênio é constituinte da molécula de clorofila que é um pigmento fotossintético, isto pode ter ocasionado uma baixa produção de fotoassimilados que prejudicou o desenvolvimento da parte aérea destas plantas.

Já o incremento da massa seca radicular em relação as dosagens de adubação nitrogenada foi, provavelmente, consequência da relação direta com o aumento da matéria seca da parte aérea, visto que o maior desenvolvimento da parte aérea, tanto em número de folhas quanto em área foliar propiciou incremento na produção de fotoassimilados. Estes por sua vez foram deslocados, em parte, para o sistema radicular proporcionando um melhor desenvolvimento deste que por sua vez proporcionou maior absorção de água e nutrientes para a parte aérea.

\section{CONCLUSÕES}

A aplicação de dosagens de nitrogênio maiores que a recomendada não influenciaram em emissões de óxido nitroso prejudiciais ao ambiente.

\section{AGRADECIMENTOS}

À UFC, pela contribuição em minha formação acadêmica. À CAPES, pela concessão de bolsa de mestrado; ao CNPq (processo $n^{\circ} 562501 / 2010-0$ ) e à Embrapa Agroindústria Tropical (info SEG $\mathrm{n}^{\circ}$ 02.09.01.027.00.00) pelo apoio financeiro à execução do projeto.

\section{REFERÊNCIAS}

ANDA_Associação Nacional para Difusão do Adubo. Estatística: principais indicadores do setor de fertilizantes. $2014 . \quad$ Disponível em: $<$ http://www.anda.org.br/estatistica/Principais_Indicadore s_2014.pdf $>$. Acesso em: 21 out. 2014.

BARTON, L.; KIESE, R.; GATTER, D.; BUTTERBACKBAHL, K.; BUCK, R.; HINZ, C. e MURPHY, D. V. Nitrous oxide emissions from a cropped soil in a semiarid climate. Global Change Biology.14, 177-192, 2008.

BEZERRA, A. D. M. Uso das abelhas jandaíra (Meliponas ubnitida) e canudo (scaptotrigona sp.) para a polinização da minimelancia (Citrullus lanatus (Thun.) Mats \&Nakai) em cultivo protegido. 2011. 62 f. Monografia - Universidade Federal do Ceará, Fortaleza, 2011.

COSTA, A. R. Produção de óxido nitroso de solo cultivado com feijoeiro comum irrigado em sistema plantio direto no cerrado. 2011. 82 f. Dissertação (Mestrado em Agronomia) - Universidade Federal de Goiás, Goiânia, 2011.

CRISÓSTOMO, L. A.; SANTOS, A. A. dos; RAIJ, B. V.; FARIA, C. M. B. de; SILVA, D. J. da; FERNANDES, F. A. M.; SANTOS, F. J. S.; CRISÓSTOMO, J. R.; FREITAS, J. A. D. de; HOLANDA, J. S. de; CARDOSO, J. W.; COSTA, N. D. Adubação, irrigação, híbridos e práticas culturais para o meloeiro no nordeste. Fortaleza: EMBRAPA, 2002. 21 p. (Circular Técnica 14)

EMBRAPA_Empresa Brasileira de Pesquisa Agropecuária. Primeiro inventário brasileiro de emissões antrópicas de gases de efeito estufa: emissões de óxido nitroso $\left(\mathrm{N}_{2} \mathrm{O}\right)$ provenientes de solos agrícolas. Brasília: Ministério de Ciência e Tecnologia. 2006. 129 p.
FERNANDES, O. B.; PEREIRA, F. H. F.; JÚNIOR, W. P. A.; QUEIROGA, R. C. F.; QUEIROGA, F. M. Efeito do nitrato de cálcio na redução do estresse salino no meloeiro. Revista Caatinga, Mossoró, v. 23, n. 3, p. 93$103,2010$.

FIGUEIREDO, E. B. Balanço de gases de efeito estufa e emissões de $\mathrm{CO}_{2}$ do solo nos sistemas de colheita da cana de açúcar manual queimada e mecanizada crua. 2012. 96 f. Tese (Doutorado em Agronomia) Universidade Estadual Paulista, Faculdade de Ciências Agrárias e Veterinárias, Jaboticabal, 2012.

FILHO, J. V. P.; BEZERRA, F. M. L.; SILVA, A. R. A.; SOUSA, C. C. M.; CASTRO, J. M. Frequência de irrigação e aplicação de $\mathrm{N}$ em meloeiro irrigado por gotejamento nas condições semiáridas do Nordeste. Científica, Jaboticabal, v. 42, n. 1, p. 11-22, 2014. DOI: http://dx.doi.org/10.15361/1984-5529.2014v42n1p11-22

FILHO, O. M. M.; COSTA, J. T. A.; JUNIOR, A. T. C.; BEZERRA, M. A.; MESQUITA, R. C. M. Caracterização biométrica, crescimento de plântulas e pega de enxertia de novos porta-enxertos de cajueiro anão precoce. Revista Ciência Agronômica, Fortaleza, CE, v. 37, n. 3, p. 332-338, 2006.

GRATIERI, L. A. Nitrogênio e potássio para meloeiro cultivado em fibra de coco, sem drenagem. 2012. $89 \mathrm{f}$. Tese (Doutorado em Agronomia) - Faculdade de Ciências Agrárias e Veterinárias, Jaboticabal, 2012.

IPCC_International Panel Climate Change. Climate Change: The physical science basis. 2007. Disponível em: $<$ http://www.ipcc.ch/publications_and_data/publications ipcc_fourth_assessment_report_wg1_report_the_physical science basis.htm>. Acesso em: 24 out. 2014 .

IPC $\bar{C}$ International Panel Climate Change. Understanding climate change - 22 years of IPCC assessment. 2006. Disponível em: $<$ http://www.ipcc.ch/pdf/press/ipcc_leaflets_2010/ipccbrochure_understanding.pdf $>$. Acesso em: 27 out. 2014.

LIU, C; ZHENG, X.; ZHOU, Z.; HAN, S.; WANG, Y.; WANG, K.; LIANG, W.; LI, M.; CHEN, D.; YANG, Z. Nitrous oxide emissions from an irrigated cotton Field in Northen China. Plant and Soil, The Hague, v. 332, n. 1-2, p. 123-134. 2010

LUDWING, J.; MEIXNER, F. X.; VOGEL, B.; FORSTNER, J. Soil-air exchange of nitric oxide: an overview of processes, enviromentalfators and modeling study. Biogeochemistry, Dordrechet, v. 52, n. 3, p. 225-257. 2001. DOI: https://doi.org/10.1023/A:1006424330555

MADARI, B. E.; COSTA, A. R. da; JANTALIA, C. P.; MACHADO, P. L. O. de A.; CUNHA, M. B. da; MARTINS, D. R.; SANTOS, J. H. G. dos; ALVES, B. J. R. Fator de emissão de óxido nitroso (N2O) para a fertilização com $N$ na cultura do feijoeiro comum irrigado no cerrado. Santo Antônio de Goiás: Embrapa Arroz e Feijão, 2007. 4 p. (Comunicado Técnico 144).

OKUMURA, R. S.; MARIANO, D. de C. Aspectos agronômicos da ureia tratada com inibidor de urease. Ambiência Guarapuava, Paraná, v. 8, n. 2, p. 403-414, 2012

SOUZA, W. J. O.; MELO, W. J. Teores de nitrogênio no solo e nas frações da matéria orgânica sob diferentes sistemas de produção de milho. Revista brasileira de ciência do solo, Viçosa, v. 24, n. 4, p. 885-896, 2000. DOI: http://dx.doi.org/10.1590/S0100-06832000000400020 
SANTOS, C. E.; KIST, B. B.; SANTOS, C. E.; REETZ, E. SILVA, M. de C. Melão rendilhado em ambiente R.; CARVAlHO, C.; SILVEIRA, D. N. Anuário brasileiro da fruticultura 2013. Santa Cruz do Sul: Editora Gazeta Santa Cruz, 2013. 136 p.

SANTOS, T. L.; BARROS, V. D. S.; FIGUEIRÊDO, M. C. B. de.; NUNES, A. D. A.; GONDIM, R. S.; ARAGAO, F. A. S. de.; SOUSA, J. A. de. Pegada de carbono de produtos agrícolas: estudo de caso do melão. Fortaleza: Embrapa Agroindústria Tropical, 2013. 34 p. (Documentos 167). protegido submetido a doses de nitrogênio e potássio em Rondonópolis - MT. 2012. 103 f. Dissertação (Mestrado em Engenharia Agrícola) - Universidade Federal de Mato Grosso, Rondonópolis, 2012.

TEMÓTEO, A. S.; MEDEIROS, J. F.; DUTRA, I.; OLIVEIRA, $\mathrm{F}$ de A. Crescimento e acúmulo de nitrogênio e potássio pelo melão pele de sapo fertirrigado. Irriga, Botucatu, v. 15 , n. 3, p. 275-281, 2010. DOI: https://doi.org/10.15809/irriga.2010v15n3p275 